\title{
SÚMULA DO NÚMERO 343 DO SUPERIOR TRIBUNAL DE JUSTIÇA E SÚMULA VINCULANTE No 5: a ausência de Advogado no Processo Administrativo Disciplinar acarreta Cerceamento de Defesa?
}

\author{
Maria Fernanda Pereira Rosso ${ }^{1}$ \\ Maurício Siqueira $^{2}$ \\ Rossana Birck de Menezes ${ }^{3}$ \\ Vanessa Bertolo de Andrade ${ }^{4}$
}

RESUMO: A ampla defesa e o contraditório são garantidos no processo administrativo, conforme disposição constitucional (art. $5^{\circ}, \mathrm{LV}$ ). A Súmula $\mathrm{n}^{\circ} 343$ do Superior Tribunal de Justiça surgiu de forma a pacificar o entendimento quanto à necessidade da presença de advogado em todas as fases do processo administrativo disciplinar, sob o fundamento de que sua ausência acarretaria o cerceamento de defesa e, dessa forma, nulidade processual. Contudo, pouco tempo depois, foi editada a súmula vinculante $\mathrm{n}^{\mathrm{o}} 5$ do Supremo Tribunal Federal, dispensando a obrigatoriedade de defesa técnica por advogado no processo administrativo disciplinar. Devido a ambas as súmulas possuírem entendimentos contrários, acabaram por gerar discussões maiores entre os operadores do Direito, o que se tornou objeto de estudo deste trabalho, que apresentará conclusões dos autores quanto a problemática enfrentada.

PAlavras-Chave: Direito Administrativo, Súmula Vinculante, Processo Administrativo Disciplinar, Cerceamento de Defesa.

\section{Binding Precedent number 343 from Brazilian Supreme Court of Justice and the Binding Abridgment $n^{\circ}$ 5: the layer absence in Administrative Disciplinary Procedure generates denial of the right to be heard?}

\begin{abstract}
The legal defense and adversarial proceeding are granted in administrative procedure, according to Brazilian Constitution (article $5^{\text {th }}, \mathrm{LV}$ ). The binding precedent $\mathrm{n}^{\circ} 343$ from Brazilian Supreme Court of Justice, was raised to pacify the understanding about the need of a layer in each stage of Administrative Procedure, founded in the idea that his absence would generate the denial of the right to be heard, and, on this way, procedural nullity. However, few times later, the Binding Abridgment $\mathrm{n}^{\circ} 5$, was edited by Brazilian Federal Supreme Court, refusing the obligation of layer technical defense in disciplinary administrative procedure. Due to both - binding precedent and biding abridgment - having opposite understandings, it were originated major debates between law professionals, and that became the subject of this very study, which will present possible conclusions about these questions.
\end{abstract}

KEY WORDS: Administrative Law, Binding Abridgement, Disciplinary Administrative Procedure, Denial of the right to be heard.

\footnotetext{
${ }^{1,2},{ }^{3},{ }^{4}$ : Acadêmicos do oitavo semestre do Curso de Direito Diurno da Universidade Federal de Santa Maria
} 


\section{INTRODUÇÃO}

O processo administrativo consiste em um conjunto de atos coordenados relativamente autônomos entre si, que são praticados de forma seqüencial, para obtenção de uma decisão final no âmbito administrativo. Tais atos são essencialmente regulamentados na Lei Federal $n^{\circ}$ 9.784/99, que traz as regras do processo administrativo, para a Administração Pública Federal Direta e Indireta, alcançando também os órgãos dos Poderes Judiciário e Legislativo, e, inclusive, o Ministério Público e o Tribunal de Contas.

Entretanto, com o advento dessa lei, não houve revogação da legislação específica da matéria. Aliás, o artigo 69 da Lei determina sua aplicação de forma subsidiária aos processos administrativos especiais, como, por exemplo, o processo administrativo disciplinar e o processo administrativo fiscal, ambos regidos por diplomas legislativos próprios.

Dessa forma, no primeiro capítulo deste trabalho, serão definidos os princípios do processo administrativo, buscando seu fundamento legal e sua aplicação na jurisprudência, destacando, em especial, a presunção de legalidade do ato administrativo. No segundo capítulo, será abordado o conceito de Processo Administrativo Disciplinar, sua importância e princípios básicos que o orientam.

Por fim, com a análise da Súmula 343 do Superior Tribunal de Justiça e Súmula Vinculante $\mathrm{n}^{\circ} 5$ do Supremo Tribunal Federal (aqui também referidos pelas siglas "STJ" e "STF", respectivamente), serão discutidas a necessidade de representação por advogado, neste tipo de ação, bem como se a sua ausência estaria infringindo o contraditório e a ampla defesa. Através da conclusão, serão retomados os aspectos iniciais, e apresentada a opinião dos autores a respeito do tema desenvolvido.

\section{PRINCÍPIOS DO PROCESSO ADMINISTRATIVO}

Os princípios em que toda ciência se apóia, no entendimento de DINAMARCO (2001), são dados exteriores a ela própria, pelos quais ela se liga a uma área de conhecimento mais ampla. São as premissas que determinam o seu próprio modo-de-ser e as individualizam, constituindo-se em raízes alimentadoras de seus conceitos e de suas propostas. 
Quanto àqueles que deverão ser observados no Processo Administrativo, estão expressos no art. $2^{\circ}$ da Lei $n^{\circ}$ 9.784/99, o qual aduz que "a Administração Pública obedecerá, dentre outros, aos princípios da legalidade, finalidade, motivação, razoabilidade, proporcionalidade, moralidade, ampla defesa, contraditório, segurança jurídica, interesse público e eficiência ${ }^{5 “}$.

Ademais, há outros princípios e critérios há serem observados durante o Processo Administrativo, os quais encontram previsão na Carta Magna Brasileira. Dessa forma se encontra, por exemplo, o princípio da publicidade, o qual possui previsão no art. 37 da Constituição Federal de 1988. Apesar de não constar expressamente na legislação específica, verifica-se a possibilidade de sua aplicação com a interpretação dos incisos V e $\mathrm{X}$ do parágrafo único art. $2^{\circ}{ }^{6}$, sendo que se estende a esse ramo em decorrência do fato de que a atividade da Administração é pública.

Assim, à administração pública cabe aplicar os dispositivos legais, e, quando da fragilidade destes, recorrer aos princípios. Dessa maneira, vislumbra-se a necessidade de aplicação, também, da presunção de legitimidade e de veracidade dos atos administrativos, cuja análise é desenvolvida no próximo tópico.

\subsection{Da Presunção de Legitimidade e de Veracidade dos Atos}

\section{Administrativos}

Todos os atos administrativos, por uma imperiosa necessidade do bom andamento da administração pública, possuem uma presunção de legitimidade e de veracidade, que representam expressão da soberania e poder Estatais, além da necessidade de manter a celeridade processual.

Tais presunções acarretam consequencias, dentre as quais, segundo Di Pietro (2011) , é possível elencar: a produção de efeitos, enquanto não decretada a invalidade do

\footnotetext{
${ }^{5}$ Legalidade (também prevista no art. 37, caput, CF/88), finalidade (ou impessoalidade, art. 37, caput, $\mathrm{CF} / 88$ ), motivação (art. 93, X, CF/88), razoabilidade e proporcionalidade (decorrentes da doutrina e jurisprudência), moralidade (art. 37, caput, CF/88), ampla defesa e contraditório (art. $5^{\circ}, \mathrm{LV}, \mathrm{CF} / 88$ ), segurança jurídica (art. $5^{\circ}, \mathrm{XXXVI}, \mathrm{CF} / 88$ ), interesse público (supremacia do interesse público sobre o particular e indisponibilidade do interesse público) e eficiência (art. 37, caput, CF/88).

${ }^{6}$ Art. $2^{\circ}$, parágrafo único: Nos processos administrativos serão observados, entre outros, os critérios de:

(...) V- divulgação oficial dos atos administrativos, ressalvadas as hipóteses de sigilo previstas na Constituição;

(...)
} 
ato administrativo; a impossibilidade de apreciação ex officio da validade, que só pode ser decretada quando pedida pelo interessado, e a inversão do ônus da prova à quem alega sua invalidade.

Significa dizer que até que apareça um elemento capaz de fornecer prova cabal de sua ilegalidade, a legalidade é incontestável. Somente mediante uma cognição exauriente, que conclua fundamentadamente, pode ser capaz de infirmar essa presunção.

Para isso, é necessário que a parte interessada prove os fatos alegados, o que não exime a Administração da prova de sua defesa. A presunção atinge inclusive os atos privados, pois ela é inerente ao Poder Público, independentemente da natureza de seus atos.

A justificativa para esse atributo encontra guarida na mais prestigiosa doutrina administrativista nacional:

Os atos administrativos, qualquer que seja sua categoria ou espécie, nascem com a presunção de legitimidade, independente da norma legal que a estabeleça. Essa presunção decorre do princípio da legalidade da Administração, que, nos Estados de Direito, informa toda a atuação governamental.

(...)

A presunção de legitimidade autoriza a imediata execução ou operatividade dos atos administrativos, mesmo que arguidos de vícios ou de defeitos que os levem a invalidade. (MEIRELLES, 2002).

Neste sentido, a presunção de legitimidade refere-se ao fato de o ato obedecer o que é previsto em lei, sendo que, em decorrência disso, entende-se que os atos administrativos observaram o dispositivo legal até que seja provado o contrário.

Ainda, a transferência do ônus da prova da invalidade ao impugnante constitui outra inferência da presunção de legitimidade; em decorrência disso, até sua anulação o ato terá plena eficácia. Nessas circunstâncias, os princípios da ampla defesa, do contraditório, e o da legalidade, tratam, também, da construção probatória, encontrando previsão na Lei dos Processos Administrativos, bem como constitucionalmente, conforme já referido.

$\mathrm{X}$ - garantia dos direitos à comunicação, à apresentação de alegações finais, à produção de provas e à interposição de recursos, nos processos de que possam resultar sanções e nas situações de litígio 


\subsection{Do Devido Processo Legal, da Ampla Defesa e do Contraditório}

A garantia de defesa, expressa no art. $5^{\circ}$, inciso $\mathrm{LV}^{7}$ da Constituição Federal de 1988, determina o respeito ao contraditório e à ampla defesa, preservando-se o devido processo legal. Ambos os princípios estão relacionados à existência de partes contrárias no litígio, às quais deve ser oportunizada a plena capacidade para se manifestar.

A ampla defesa decorre da tutela jurídica do direito à defesa, cuja garantia é incumbida ao Estado, sendo inerente aos processos que envolvam litígios ou sanção daquele, não podendo ter ser limitada. Por advir do fato da existência de duas partes envolvidas na disputa, quando um deles alega algo, ao outro deve ser garantida a resposta.

Acerca da ampla defesa e do contraditório no processo administrativo, elucidativa a lição de Hely Lopes Meirelles:

Por garantia de defesa deve-se entender não só a observância do rito adequado como a cientificação do processo ao interessado, a oportunidade para contestar a acusação, produzir prova de seu direito, acompanhar os atos da instrução e utilizar-se dos recursos cabíveis.

$$
\text { (...) }
$$

Processo administrativo sem oportunidade de defesa ou com defesa cerceada é nulo, conforme têm decidido reiteradamente nossos Tribunais judiciais, confirmando a aplicabilidade do princípio constitucional do devido processo legal, ou, mais especificamente, da garantia de defesa. (MEIRELLES, 2002, p. 656).

Na lição de Léo da Silva Alves (p.32, 2005), “a Constituição Federal de 1988 equiparou os processos administrativos aos processos judiciais, como se observa na clara redação do art. $5^{\circ}, \mathrm{LV}$. Por conseguinte, não há diferença entre funcionário e réu. As mesmas garantias que tem o réu no processo penal tem o funcionário no processo disciplinar".

Mister destacar, neste sentido, o Princípio da Instrumentalidade das Formas, o qual está intimamente ligado à economia processual e que rege os processos, tanto judiciais, quanto administrativos. Costuma ser chamado de "princípio do informalismo", na esfera do Direito Processual Administrativo, tendo em vista a falta de rigidez processual nessa

\footnotetext{
7 Art. $5^{\circ}$, inc. LV: "LV - aos litigantes, em processo judicial ou administrativo, e aos acusados em geral são assegurados o contraditório e ampla defesa, com os meios e recursos a ela inerentes;"

8 "Informalismo não significa, nesse caso, ausência de forma; o processo administrativo é formal no sentido de que deve ser reduzido a escrito e conter documentado tudo o que ocorre no seu desenvolvimento; é informal no sentido de que não está sujeito a formas rígidas” (DI PIETRO, 2011, p. 629).
} 
área. Isso em razão de o interesse público exigir maior celeridade, sendo que os processos os quais envolvam particulares costumam demandar maior atenção às formas determinadas em lei.

A ideia basilar do princípio consiste no fato de a forma ser destinada para atingir um fim, sendo que, quando este é alcançado - mesmo havendo ocorrido violação daquelainexistem razões para anular o ato. Isso significa dizer que o importante ao Direito, enquanto instrumento de justiça, é fazer justiça, torná-la efetiva, alcançar o objetivo almejado, sendo o meio - a forma - o instrumento para tanto.

$\mathrm{Na}$ realidade, deve-se atentar para a necessidade de que sejam identificados os casos nos quais o formalismo é necessário para a preservação do interesse público, bem como naqueles casos em que a ausência da forma prevista em lei pode acarretar nulidades no processo.

Nessa medida, certos formalismos processuais devem certamente ser respeitados, havendo hipóteses em que uma vez não cumpridos, ensejam a nulidade de parte do processo ou até mesmo de sua totalidade, por isso devem ser acatados. Deve-se destacar que o fim é justamente o mais importante sendo o meio, seu instrumento.

Assim é o entendimento do Superior Tribunal de Justiça e do Tribunal de Justiça do Rio Grande do Sul, conforme as ementas abaixo transcritas:

AGRAVO EM EXECUÇÃO. PRÁTICA DE FALTA GRAVE. ALEGAÇÃO DE NULIDADE POR PRESCRIÇÃO DA CONCLUSÃO DO PROCEDIMENTO ADMINISTRATIVO DISCIPLINAR. AFASTAMENTO. Na ausência de previsão legal, adota-se como marco regulador o menor índice previsto no artigo 109 do Código Penal para apuração da prescrição da pretensão punitiva pela prática de falta grave, intervalo que não ocorreu no caso. NULIDADE POR AUSÊNCIA DE CIENTIFICAÇÃO PRÉVIA E DEFESA TÉCNICA. AFASTAMENTO. Deflui-se dos autos que o apenado foi previamente cientificado tendo, inclusive, sido defendido por defesa técnica tanto na esfera administrativa quando judicial. Assim, inexiste prejuízo que causa nulidade. PRÁTICA DE FALTA GRAVE. DESRREPEITO A SERVIDOR. CONFIGURAÇÃO. MANUNTENÇÃO DO CONSECTÁRIO LEGAL DE ALTERAÇÃO DA DATA-BASE PARA FUTUROS BENEFÍCIOS LEGAIS, SALVO O LIVRAMENTO CONDICILNAL E AQUELES DECORRENTES DE DECRETOS PRESIDENCIAIS. Agravo improvido. (Agravo $N^{o} 70043933852$, Primeira Câmara Criminal, Tribunal de Justiça do RS, Relator: Marco Antônio Ribeiro de Oliveira, Julgado em 05/10/2011). 
ADMINISTRATIVO - PROCESSUAL CIVIL - AÇÃO CIVIL PÚBLICA - DANO AO MEIO AMBIENTE - JUNTADA DE DOCUMENTOS NOVOS - FALTA DE INTIMAÇÃO DA PARTE CONTRÁRIA - AUSÊNCIA DE DEMONSTRAÇÃO DE PREJUÍZO - NULIDADE - DESNECESSIDADE.

1. A declaração da nulidade dos atos processuais depende da demonstração da existência de prejuízo à parte interessada, conforme dispõe o art. $249, \$ 1^{\circ}$, do $C P C$, in verbis: "O ato não se repetirá nem se lhe suprirá a falta quando não prejudicar a parte". Assim, não há nulidade se não estiver demonstrado o prejuizo. É o que sintetiza o princípio pas de nullité sans grief.

2. A Recorrente não demonstrou a ocorrência de prejuízo causado pela juntada de documentos novos, portanto, não há falar em nulidade. Recurso especial improvido.

(REsp 725984 / PR ; RECURSO ESPECIAL 2005/0026692-8; Relator: Ministro HUMBERTO MARTINS (1130); Segunda Turma; Julgado em: 12/09/2006).

Desse modo, entende-se que a declaração de nulidade de qualquer ato processual depende da demonstração de prejuízo. Entretanto, é difícil dimensionar o direito à ampla defesa e ao contraditório, e, consequentemente, os casos em que ambos acabam violados e geram cerceamento de defesa.

Em relação a isso Superior Tribunal de Justiça e o Supremo Tribunal Federal, por meio de edição de súmulas, face à ausência legislativa, dispõem- de forma diversa- quanto à necessidade de advogado no processo administrativo disciplinar o que faz com que, nesse sentido, persista a indagação quanto se a ausência da representação profissional acarreta cerceamento de defesa.

\section{DO PROCESSO ADMINISTRATIVO DISCIPLINAR :}

\subsection{Noções gerais do Processo Administrativo Disciplinar}

A autoridade que, na sua jurisdição, tiver ciência de irregularidade no serviço público, é obrigada a promover a sua apuração imediata, mediante instauração de sindicância ou processo administrativo disciplinar (neste estudo, também referido pela sigla "PAD”). Tratam-se, assim, de meios de apuração de faltas cometidas pelos agentes público no exercício de suas atribuições. 
O PAD consiste em um processo obrigatório para a aplicação de penas de cargo para o servidor estável ${ }^{9}$, e está previsto na Lei $\mathrm{n}^{\circ} 8.112 / 90$, com relação aos servidores públicos do âmbito federal. De acordo com esta lei, será exigido o processo administrativo disciplinar para a aplicação das penas de suspensão por mais de 30 dias, demissão, cassação, aposentadoria ou disponibilidade e destituição de cargo em comissão.

Entende o doutrinador José dos Santos Carvalho Filho (2011) que o PAD, cujo formalismo é necessário para garantia da ampla defesa, é o meio fundamentado na relação de disciplina entre Estado e seus servidores para que se apure as infrações, bem como se apliquem as sanções, aos servidores, pela Administração Pública. Conforme a opinião do autor:

Cabe à Administração zelar pela correção e legitimidade da atuação de seus agentes, de modo que quando se noticia conduta incorreta ou ilegítima tem a Administração o poder jurídico de restaurar a legalidade e de punir os infratores. A hierarquia administrativa, que comporta vários escalões funcionais, permite esse controle funcional com vistas à regularidade no exercício da função administrativa. A necessidade de formalizar a apuração através de processo administrativo é exatamente para que a Administração conclua a apuração dentro dos padrões de maior veracidade. (CARVALHO FILHO, 2011, p. 905-906).

Assim, a importância do processo administrativo disciplinar reside no fato de que é necessário o bom funcionamento da Administração Pública, a qual deve buscar a boa conduta de seus agentes, que, por sua vez, serão punidos em caso de alguma irregularidade constatada $^{10}$. A hierarquia entre as instituições e funções garante que o processo administrativo disciplinar possa ser apurado.

Um dos princípios que o rege é o da imparcialidade, garantido pela instauração de comissões disciplinares, sendo existentes cinco fases para seu desenvolvimento: instauração, instrução, defesa, relatório e decisão.

\footnotetext{
9 “Art. 41. São estáveis após três anos de efetivo exercício os servidores nomeados para cargo de provimento efetivo em virtude de concurso público.§ $1^{\circ} \mathrm{O}$ servidor público estável só perderá o cargo: II - mediante processo administrativo em que lhe seja assegurada ampla defesa."

${ }^{10}$ Conforme José dos Santos Carvalho Filho: "O fundamento do processo em foco está abrigado no sistema disciplinar que vigora na relação entre o Estado e seus servidores. Cabe à Administração zelar pela correção e legitimidade da atuação de seus agentes, de modo que quando se noticia conduta incorreta ou ilegítima tem a Administração o poder jurídico de restaurar a legalidade e de punir os infratores. (.. ) A necessidade de formalizar a apuração através de processo administrativo é exatamente para que a Administração conclua a apuração dentro dos padrões de maior veracidade." (2011, p. 905-906).
} 
Além disso, a ampla defesa é garantida pela necessidade de que seja seguida a forma prevista em lei, bem como através da vista do processo ao indiciado, após a instrução, a fim de que apresente a defesa. O art. 22, da Lei 8.112/90 ${ }^{11}$, deixa bem claro que, para um servidor público estável perder sua função, é necessário processo em que lhe seja garantido a ampla defesa. Ademais, quando do julgamento, é preciso que a autoridade julgadora examine o processo por completo, a fim de declarar sua nulidade, bem como saneá-lo, ou determinar a realização de novas diligências, caso necessário.

\subsection{A Súmula $n^{\circ} 343$ do Superior Tribunal de Justiça.}

Em 12 de setembro de 2007, o Superior Tribunal de Justiça (STJ) aprovou a súmula $n^{\circ} 343$ com o seguinte enunciado: "É obrigatória a presença de advogado em todas as fases do processo administrativo disciplinar."

O Ministro Hamilton Carvalhido, no julgamento do Mandado de Segurança $n^{\circ}$ 7078/DF, do qual foi relator, observou que:

No que diz respeito à ocorrência de cerceamento de defesa, é de se reconhecer que durante a instrução do inquérito, a impetrante não se viu acompanhar de defensor constituído, que, a nosso ver, é imperativo constitucional, com o qual não se compatibiliza a autodefesa, em se cuidando de acusado sem habilitação científica em Direito.

(...)

A presença obrigatória de advogado constituído ou defensor dativo, por óbvio, é elementar à essência mesma da garantia constitucional do direito à ampla defesa, com os meios e recursos a ela inerentes, quer se trate de processo judicial ou administrativo, porque tem como sujeitos não apenas os litigantes, mas também os acusados em geral.

O Superior Tribunal de Justiça entendia que, em observância aos princípios da ampla defesa e do contraditório, é indispensável a presença de advogado ou de defensor dativo inclusive na fase instrutória em processo administrativo disciplinar, não obstante a ausência de expressa determinação legal. Esse entendimento decorre da circunstância de que é exatamente na fase probatória que se colhem os elementos que servirão de suporte para a futura aplicação da penalidade administrativa.

\footnotetext{
${ }^{11}$ Lei 8112/90: Art. 22. O servidor estável só perderá o cargo em virtude de sentença judicial transitada em julgado ou de processo administrativo disciplinar no qual lhe seja assegurada ampla defesa.
} 
Para o STJ, a simples determinação legal facultando ao servidor acompanhar o processo disciplinar desde sua instauração pessoalmente ou por seu procurador não satisfaz a exigência constitucional inserida no art. $5^{\circ}$, inc. LV, da Constituição Federal. O princípio da ampla defesa no processo administrativo disciplinar se materializa não apenas com a oportunização ao acusado de fazer-se representar por advogado legalmente constituído desde a instauração do processo, mas com a efetiva constituição de defensor durante todo o seu desenvolvimento.

Além disso, o Superior Tribunal de Justiça possuía jurisprudência uniforme no sentido de que os princípios constitucionais da ampla defesa e do contraditório, igualmente incidentes na esfera administrativa, tornam obrigatória a presença de advogado constituído ou defensor dativo, sob pena de se declarar a nulidade de todo o processo.

Contudo, com a edição da súmula vinculante $n^{\circ} 5$ do Supremo Tribunal Federal (cuja análise será desenvolvida posteriormente), o Superior Tribunal de Justiça adotou o entendimento de que "não há mais que se falar em indispensabilidade, no Procedimento Administrativo Disciplinar, de que a defesa do indiciado seja necessariamente realizada por Advogado" (Mandado de Segurança 13.791 do Distrito Federal, julgado em 13/04/2011).

\subsection{A discussão acerca da Súmula Vinculante $n^{\circ}$ 5, do Supremo Tribunal Federal.}

A súmula vinculante foi introduzida no ordenamento jurídico por meio da Emenda Constitucional $n^{\circ} .45$, que incluiu o art. 103- $\mathrm{A}^{12}$ na Constituição da República, originando inúmeros debates acerca dos prós e contras de sua instituição.

O objetivo maior de sua implementação é a necessidade de pacificar a insegurança jurídica gerada por decisões jurisprudenciais conflitantes entre os órgãos jurídicos, ou entre esses e a administração pública, impedindo a multiplicação desnecessária de processos.

Contudo, alegam-se como problemas decorrentes das Súmulas Vinculantes devido a determinação de serem iguais casos que na verdade não o são (chamados "causas

\footnotetext{
12 “Art. 103-A, caput. O Supremo Tribunal Federal poderá, de ofício ou por provocação, mediante decisão de dois terços dos seus membros, após reiteradas decisões sobre matéria constitucional, aprovar súmula que, a partir de sua publicação na imprensa oficial, terá efeito vinculante em relação aos demais órgãos do Poder Judiciário e à administração pública direta e indireta, nas esferas federal, estadual e municipal, bem como proceder à sua revisão ou cancelamento, na forma estabelecida em lei"
} 
repetitivas"), porquanto em sua grande maioria são apenas similares, sendo esse o preço pago na busca pela celeridade, a qual é pretensiosamente proporcionada pelo instituto.

Em sua defesa, os apoiadores asseveram que seus efeitos são positivos, pois eliminariam a "loteria jurídica", ou seja, decisões opostas em situações fáticas exatamente iguais. Porém, o que se pode observar é que as Súmulas Vinculantes acabam por limitar o poder de decisão dos magistrados de primeiro grau, os quais se vêem obrigados a seguir o entendimento do Supremo Tribunal Federal, bem como que elas causariam o "engessamento" da jurisprudência. Outrossim, poderia haver a vinculação das decisões do STF ao Executivo, com a finalidade de suprir seus anseios políticos e econômicos.

Em que pese existirem discussões e opiniões contraditórias quanto aos benefícios ou prejuízos decorrentes da aplicação de Súmulas Vinculantes, em maio de 2008 houve a edição da Súmula Vinculante número 5, a qual dispôs que: "A falta de defesa técnica por advogado em processo administrativo disciplinar não ofende a Constituição”, o que veio a contrariar totalmente o entendimento do STJ externado, meses antes, pela súmula 343. Nesse sentido, impende destacar que a Lei 9.784/99 não impõe obrigatoriedade quanto à presença de advogado em processos administrativos.

O entendimento da súmula $n^{\circ} .5$ foi firmado pelo Supremo Tribunal Federal ao dar provimento ao Recurso Extraordinário $n^{\circ}$. 40, interposto contra acórdão da $3^{\text {a }}$ Seção do Superior Tribunal de Justiça, que concedera Mandado de Segurança para anular a penalidade de demissão aplicada a uma agente administrativa do Instituto Nacional do Seguro Social de São Paulo (INSS/SP). Ao julgar o Mandado de Segurança, o STJ concedeu a ordem por entender que o acompanhamento de defensor constituído é imperativo constitucional estabelecido no artigo $5^{\circ}$, inciso $\mathrm{LV}$, da CF/88, como também que o art. 133 preceitua que o advogado é indispensável à administração da justiça.

Dessa decisão, o INSS/SP e a Advocacia Geral da União interpuseram Recurso Extraordinário, resultando na mudança de entendimento pelo Supremo Tribunal Federal acerca da indispensabilidade da defesa técnica realizada por advogado no Processo Administrativo Disciplinar. Assim, súmula 343 do Superior Tribunal de Justiça restou revogada.

A Ordem dos Advogados do Brasil, por sua vez, propôs Ação de Cancelamento de Súmula Vinculante, com o fundamento que a Súmula Vinculante $\mathrm{n}^{\circ} .5$ violaria princípios 
constitucionais, dentre eles o do devido processo legal, o do contraditório e o da ampla defesa. Portanto, não existiriam pressupostos constitucionais que fundamentassem o entendimento gerado pelo Supremo Tribunal Federal.

O processo de cancelamento continua em andamento. Alternativamente, a Ordem pede que, em caso de não acolhidas as razões do pedido, seja alterado o enunciado da Súmula, passando a constar que "se houver advogado constituído, a sua não intimação nulifica o processo".

Conforme o doutrinador Marcelo Bernardes Batista (2011) com a equiparação entre os processos judiciais e administrativos pela Constituição Federal os princípios do devido processo legal aplicam-se indistintamente ao processo judicial e ao processo administrativo disciplinar, não podendo o haver interpretação diversa. Dessa forma, a ausência de defesa técnica por advogado violaria o princípio da ampla defesa e, por conseguinte, o devido processo legal.

Há quem diga que o acusado tem a faculdade de fazer a defesa pessoalmente, o que certamente é muito inseguro. Uma pessoa leiga tecnicamente não pode promover sua defesa de maneira ampla e técnica conforme determina o artigo 153 da Lei 8.112/90 e o inciso LV, do art. $5^{\circ}$, da nossa Constituição.

Ademais, além da defesa de mérito, há a defesa processual, onde o servidor processado tem o direito de, a exemplo, permanecer calado, de não produzir provas contra si mesmo, de protestar pela ordem, pedir reformulação de perguntas pelo presidente da Comissão, contraditar testemunhas. O servidor, por si mesmo, não teria habilidade para alegar todas essas matérias de defesa durante uma audiência.

Outro ponto controvertido é que não foram preenchidos, pelo Supremo Tribunal Federal, um dos requisitos formais exigidos constitucionalmente, pois não existiam reiteradas decisões, naquele tribunal, sobre a questão que foi sumulada. Três foram os precedentes em que se baseou a edição da súmula, os quais não eram necessariamente processos administrativos disciplinares: o Mandado de Segurança $n^{\circ}$ 24.961/DF trata de tomada de contas e o Agravo de Instrumento $n^{\circ}$ 207.197/PR refere-se a contencioso administrativo fiscal. Apenas o Agravo Regimental $n^{\circ}$ 244.027/SP configura situação de PAD, visto tratar da punição a policial militar (desligamento do curso de formação de oficiais). 
Contrariamente, alega-se como argumento favorável à Súmula a real dispensabilidade do advogado no processo administrativo, em vista de as decisões proferidas imporem sanção disciplinar, podendo ser reapreciadas em sede jurisdicional. A justificativa para entendimento é encontrada no art. $5^{\circ}, \mathrm{XXXV}^{13}$, da Constituição Federal, através do princípio da inafastabilidade de apreciação pelo Poder Judiciário.

Outro raciocínio a favor da súmula seria aquele atinente ao princípio do formalismo moderado, previsto no art. $2^{\circ}$, VIII e IX, da Lei $9.784^{14}$, segundo o qual devem ser adotadas formas simples, porém eficazes, para se resolver o conflito. Assim, pode-se entender que a presença de advogado no processo administrativo disciplinar, seria formalismo exagerado.

\section{CONCLUSÃO}

A ausência de advogado no processo administrativo disciplinar, por si só, não acarreta cerceamento de defesa. $\mathrm{O}$ acusado tem a prerrogativa de atuar por si mesmo ou eleger como representante aquele que considera que irá melhor defender seus interesses, não sendo necessariamente um advogado.

Se o acusado participou de todas as fases do processo administrativo e optou, mesmo tendo condições, por não constituir advogado, não poderá alegar nulidade para beneficiar-se.

Contudo, como garantia do princípio do contraditório, em caso de revelia, assim como, nos casos em que o acusado declare que não está habilitado para exercer sua própria defesa e que não tem como pagar os serviços de um advogado, deverá ser obrigatoriamente nomeado defensor dativo, sob pena de cerceamento de defesa, e consequentemente, nulidade do processo.

\footnotetext{
${ }^{13}$ Art. 5 XXXV, CF/88: “A lei não excluirá da apreciação do Poder Judiciário lesão ou ameaça a direito.” 14 “Art. 2 $2^{\underline{0}}$ A Administração Pública obedecerá, dentre outros, aos princípios da legalidade, finalidade, motivação, razoabilidade, proporcionalidade, moralidade, ampla defesa, contraditório, segurança jurídica, interesse público e eficiência.

VII - indicação dos pressupostos de fato e de direito que determinarem a decisão

$\mathrm{X}$ - garantia dos direitos à comunicação, à apresentação de alegações finais, à produção de provas e à interposição de recursos, nos processos de que possam resultar sanções e nas situações de litígio;”
} 
Como afirmado no item 2.3, está em andamento processo de cancelamento da Súmula Vinculante $n^{\circ} .5$ proposto pela Ordem dos Advogados do Brasil. Alternativamente, a Ordem pede que, caso não forem acolhidas as razões do pedido, seja modificado o enunciado.

Este configura a medida mais correta a ser adotada, pois seria o meio termo entre a segurança proporcionada pela aplicação dos princípios do contraditório e da ampla defesa, e garantir a celeridade a que visa a Súmula Vinculante $n^{\circ} .5$. O efeito, por sua vez, deve ser "ex nunc", a fim de não obrigar o Judiciário a julgar novamente os processos em que a matéria controvertida esteja presente, originando insegurança jurídica.

\section{REFERÊNCIAS}

ALVES, Léo da Silva. Sindicância e Processo Disciplinar em 50 Súmulas. Brasília: Brasília Jurídica, 2005.

ASSIS, Araken de. Cumulação de Ações. $3^{a}$ ed. São Paulo: Revista dos Tribunais, 1998.

BATISTA, Marcelo Bernardes. O direito ao devido processo legal no processo administrativo disciplinar previsto na Lei $n^{o}$. 8.112/90. Disponível em:

<http://direitounebjua.blogspot.com/2011/04/o-direito-ao-devido-processo-legal-no.html>. Acesso em: 03 de out. de 2011.

CARnElutTI, Francesco. Sistema de Direito Processual Civil, Tradução de Hiltomar Martins Oliveira. São Paulo : Classicbook, 2000.

CARVAlHO FILHO, José dos Santos. Manual de direito administrativo. $24^{\text {a }}$ ed. São Paulo: Lumen Juris, 2011.

CASTRO, Claudio Dias. Súmulas Vinculantes: Uma (Dis)Solução Jurídica. Disponível em: $<$ http://www.veirano.com.br/veirano/Home/Biblioteca/Artigos/tabid/47/ArtigoId/311/Defa ult.aspx>. Acesso em 31 de out. 2011.

A Reforma do Judiciário e a súmula vinculante - vinculação do Judiciário ou "longa manu" do Executivo ? ( $2^{\circ}$ Rafael M.). Disponível em:

<http://www.franca.unesp.br/revista/ejur/Reforma\%20do\%20Judici\%C3\%A1rio\%20(2\%C 2\%BA\%20-\%20Rafael\%20M.).htm>. Acesso em: 31 de out. de 2011. 
CUBAS, Maria Eduarda Zaina; ANDRADE, Luiz Gustavo de. A súmula vinculante $n^{\circ} 5$ e seus reflexos no processo administrativo disciplinar. Disponível em: <http://www.paranaonline.com.br/canal/direito-e-justica/news/418198/?noticia=A+SUMULA+VINCULANTE +NO+5+E+SEUS+REFLEXOS+NO+PROCESSO+ADMINISTRATIVO+DISCIPLINAR. >Acesso em: 01 de nov.2011.

DINAMARCO, Cândido Rangel. Instituições de Direito Processual Civil. Vol. 1. Malheiros, 2001.

MELlo, Celso Antônio Bandeira de. Curso de Direito Administrativo. $12^{\text {a }}$ ed. São Paulo: Malheiros, 1999.

MEIRELES, Hely Lopes. Direito administrativo brasileiro. $27^{\text {a }}$ ed. São Paulo: Malheiros,2002.

PASSOS, Calmon de. Comentários ao Código de Processo Civil. 8 a ed., V. III, n 111.4. Rio de Janeiro: Forense, 1998.

PIETRO, Maria Sylvia Zanella di. Direito Administrativo. $25^{\mathrm{a}}$ ed. São Paulo: Atlas, 2011.

RIO GRANDE DO SUL. Tribunal de Justiça. Marco Antônio Taveira Quevedo E Ministério Público. Agravo No 70043933852, Primeira Câmara Criminal, Tribunal de Justiça do RS, Relator: Marco Antônio Ribeiro de Oliveira, Julgado em 05/10/2011. Disponível

em: https://www1.tjrs.jus.br/site_php/consulta/consulta_processo.php?nome_comarca=Tribunal + de+Justi\%E7a\&versao=\&versao_fonetica $=1 \&$ tipo=1\&id_comarca=700\&num_processo_ mask $=70043933852 \&$ num_processo $=70043933852 \&$ codEmenta $=4404297 \&$ temInt $T$ eor $=\operatorname{tr}$ ue. Acesso em: 20 de out. de 2011.

Ministério Público E Jeferson Rosa dos Santos. Agravo No 70044564268, Sexta Câmara Criminal, Tribunal de Justiça do RS, Relator: Aymoré Roque Pottes de Mello, Julgado em 22/09/2011. Disponível em: http://www1.tjrs.jus.br/site_php/consulta/consulta_processo.php? nome_comarca=Tribunal+de+Justi\%E7a\&versao=\&versao_fonetica=1\&tipo=1\&id_comar $\mathrm{ca}=700 \&$ num_processo_mask $=70044564268 \&$ num_processo $=70044564268 \&$ codEmenta $=$ 4377962\&temIntTeor=true. Acesso em: 20 de out. 2011.

Município de Alecrim E Eduardo Henrique Colombo. Apelação Cível № 70034010934, Terceira Câmara Cível, Tribunal de Justiça do RS, Relator: Matilde Chabar Maia, Julgado em 26/05/2011. Disponível em: http://www1.tjrs.jus.br/site_php/consulta/consulta_processo.php ?nome_comarca=Tribunal+de+Justi\%E7a\&versao=\&versao_fonetica=1\&tipo=1\&id_coma 
rca=700\&num_processo_mask=70034010934\&num_processo=70034010934\&codEmenta =4172329\&temIntTeor=true. Acesso em: 20 de out. 2011 .

SANTOS, Ernane Fidélis. Manual de Direito Processual Civil. $5^{\mathrm{a}}$ ed. São Paulo: Editora Saraiva, 1997.

Primeiras Linhas de Processo Civil. $27^{\mathrm{a}}$ ed., $2^{\mathrm{o}}$ volume. São Paulo: Editora Saraiva, 2011.

THEODORO JÚNIOR, Humberto. Curso de Direito Processual Civil. $30^{\mathrm{a}}$ ed. Rio de Janeiro: Forense, 1999. 